\title{
The Impact of Formal Education on Computer Literacy
}

\author{
doi:10.3991/ijet.v5s2.1253 \\ M. Milić and I. Škorić \\ Mellinia d.o.o, Pula, Croatia
}

\begin{abstract}
In this paper we will present the survey conducted on 149 students in Croatia. This research includes eight grade students of elementary schools, fourth-grade students of secondary schools and second year university students, as the relevant age groups.
\end{abstract}

Given that these age groups through the course of their schooling to some extent pass some form of IT training, we wanted to explore how it affected their overcoming of computer literacy. The main goal was to investigate how and how much formal education affect the knowledge of computer literacy in diffrent age groups.

Index Terms-computer, education

\section{INTRODUCTION}

"Defining computer literacy is like trying to define "life," "space" or "energy" - pursuits that may be entertaining but don't really bring much to the bottom line or shorten your to-do list....Computer literacy may be hard to define, but computer illiteracy is costly" [3].

Literacy can be defined as "The condition or quality of being knowledgeable in a particular subject or field." [14]. Computer literacy was a term defined by Luehrmann [8], who originally believed that "computer literacy was equivalent to programming skills and use of [computer software] such as word processing." Later, the term was expanded to cover a variety of computer skills. There are also other definitions of computer literacy, for example, Tsai [15] defines it as "the basic knowledge, skills, and attitudes needed by all citizens to be able to deal with computer technology in their daily life". Unfortunately, even if you accept this definition as absolutely correct, it is difficult to accurately say what knowledge and skills are necessary to consider someone a computer literate. All the more because the technology is rapidly changing and knowledge needed to use these technologies evolve along with it.

Computers are now everywhere around us and every day we use them at work, at school, in our spare time. We use them for various reasons and in different ways. Many areas of human interest today depend on them. Computers are now with us and they are here to stay. Computers follow us in all phases of our life and it is a a necessity for everyone today to be computer literate [11].

The computer literacy also appears to be related to computer anxiety,which is characterized by an "aversion, fear or apprehension towards interacting with computers or thinking about computers" [1], so every study of computer literacy must also take into account computer anxiety, and respondents attitude towards computers [10].
Important factor associated with computer literacy is environment of respondents [7]. Every person get knowledge about computers in different ways and from different sources [seuissreport], and this makes the study of this phenomenon even more difficult. Some studies [4] show that students who entered university are already computer liter in some areas (word processing, Internet, and e-mail skills), but lack some other computer skills which are necessary for them. Sources of knowledge of ICT technologies are complex and numerous, and knowledge is changing due to rapid changes in computer technology resources (e.g., software and applications) [2]. In addition, the amount of knowledge in particular areas that are considered desirable also increasing over time [13].

Finally, why is the computer literacy so important? Because today, every student must have a certain level of computer and information technology literacy needed for success in future life. For today's society and the success in the business world, computer literacy is a necessity. Some researchers [4] indicated that employers did not feel students have adequate computer competency skills after finishing their formal education. Therefore, the research in this area and improvement of formal education, which should respond to these challenges, is extremely important. There is widespread agreement among the public and educators that all students needed to be proficient computer users or "computer literate" [9].

Today, information technology is used every day, terefore, the IT literacy and ability to use information technology in efficient way are key skills in the modern world. It should be noted that the concept of computer literacy constantly changing due to progress in technology [6]. Knowledge that ten years ago was enough to consider a pearson computer literate, today is almost unusefull. The amount and type of required knowledge significantly changed. During the period of regular school, education system is trying through various forms of computer education to give students the necessary knowledge and make them computer literate. At the same time, students every day come into contact with computer technologies and learn about them in less formal ways outside the school. IT skills are acquired through family, through friends, colleagues, self-tuition, and through many other sources. Sources from which to get their computer skills are numerous and vary in influence and number of person to person. Formal education and outside influences, together determine the level of computer literacy of each student.

\section{OBJECTIVES OF THE STUDY}

This study examines the link between computer literacy and formal education, or how formal education has an 
impact on computer literacy. Therefore, the work includes three population groups that are in various stages of formal education. The study analyzed the respondents from different groups, and tried to find the dynamics of the relationship between education and computer literacy. Different age groups have different levels of computer literacy and there is no reason to directly compare that factor, so in this paper some other factors are examined. Study tested the differences in the use of computers in the respondents of different ages, the impact of formal education on their computer skills and their attitude towards computers as a tool for learning. By studying the various groups we tried to detect changes in these factors during the period of their formal education.

Some previous research $[5,12]$ that are made on the student population indicate the relatively small importance of formal education in computer literacy, one of the goals of this research is to investigate whether this factor changes during period of formal education.

Another important factor that this study examines are computer usage habits of respondents. Analysis of these habits and their difference in different groups of respondents can provide important information about their knowledge of computers and interests. This information can help in shaping a better formal education on computers for different age groups and overall improvement of their computer literacy.

Finally, this study examines the perception of a computer as a tool for learning. Trying to determine to what extent respondents perceive the computer as a tool that can help them in acquiring new knowledge, and whether these views evolve during their schooling.

\section{Methodology}

\section{A. Sample and method}

This survey was conducted on a random sample, and in doing so we have not had any eliminatory or preliminary questions. All surveys were rolling and properly completed. Participants in present study include 149 students. The survey was conducted in six randomly selected public students in Pula, Croatia. One student do not use computer ever, so we are exclude him from further consideration. Sample still amounts to 148 students, see at the Table I.

There were equally divided between males and females.

Females represented $50 \%(n=74)$ of the sample and males represented $50.0 \%(n=74)$ of the sample.

There was two survey in eight grade elementary public school, sample were 37 (25\%) students. Three survey in educational fourth grade students of high school with 46 (31\%) participants, in „Tehnička škola“ and „Gimnazija“. And two of them was in high school with sample of 65 (44\%).

TABLE I.

RESPONDENT DATA

\begin{tabular}{|l|c|c|c|c|c|c|c|}
\hline & & \multicolumn{2}{|c|}{ Female } & \multicolumn{2}{|c|}{ Male } & \multicolumn{2}{|c|}{ All } \\
\hline Educational level & $\begin{array}{c}\text { av. } \\
\text { age }\end{array}$ & $\mathbf{N}$ & $\mathbf{\%}$ & $\mathbf{N}$ & $\mathbf{\%}$ & $\mathbf{N}$ & $\mathbf{\%}$ \\
\hline Elementary school & 14 & 27 & 18,2 & 10 & 6,8 & 37 & 25 \\
\hline Secondary schools & 18 & 26 & 17,6 & 20 & 13,5 & 46 & 31,1 \\
\hline University & 21 & 21 & 14,2 & 44 & 29,7 & 65 & 43,9 \\
\hline & & $\mathbf{7 4}$ & $\mathbf{5 0}$ & $\mathbf{7 4}$ & $\mathbf{5 0}$ & $\mathbf{1 4 8}$ & $\mathbf{1 0 0}$ \\
\hline
\end{tabular}

The students are aged 13-27 years old. The mean age of the participants was $18(17,9)$ years old. For a more detailed description of the demografic data, see table 1 .

We design a survey instrument with 25 questions. 19 questions was like: "How much you agree with the following statements"; were made into Likert-type questions ranging from "strongly-disagree" to "strongly-agree" on a 5-point scale.

The collected data were coded and analyzed using Statistica, software package for making statistical analysis, and Microsoft Excel.

All the students had a computer in their homes, also, one student has no connection on Internet and only 9 students have a slow connection (modem).

\section{B. Variables}

Almost all questions in survey were made into Likerttype questions ranging from "strongly-agree" to "strongly-disagree" on a 5-point scale to measure how students use computer. The participants were asked whether they would agree or disagree with statements such as the following: "I use computer for : word processing ", "I use computer for: review or processing image " and so on. With respect to their age, results are expected. Most of them are use computer to surf on Internet $(\mathrm{a}=1,38)$ and listen to music and watching movies $(a=1,59)$. Least of them use computer for net banking $(a=4,2)$ and spreedsheet $(a=3,9)$.

\section{RESULTS}

It is evident, from the Table II, and the Fig. ${ }^{\circ} 1$. that the maximum number of students independently teaches (them 62.84\%), 15.54\% learning from a family member, then friend, and only at the 4-place, with $8.78 \%$ a teacher.

The importance of independent learning is growing through a period of schooling. Elementary school students count in the initial period on the other sources primary, to slowly get knowledge and become computer-written, selflearning is becoming the main source of knowledge. Notes that self-learning increases with education. Likewise, in elementary school, self-learning and other forms of assistance are equally represented, while this is not the case with secondary school, and university. Fig. ${ }^{\circ} 2$.

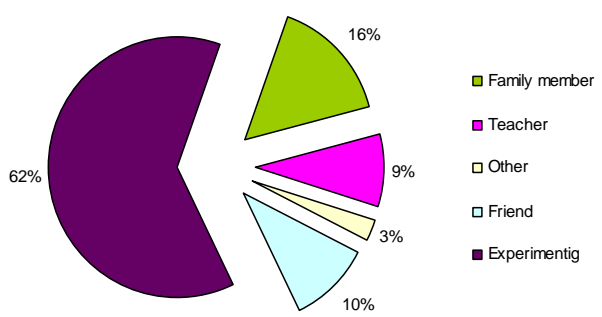

Figure 1. The relationship of different influences on computer literacy

TABLE II.

THE RELATIONSHIP OF DIFFERENT INFLUENCES ON COMPUTER LITERACY

\begin{tabular}{|l|c|c|}
\hline & number of participant & percentage \\
\hline Family member & 23 & $15,54 \%$ \\
\hline Teacher & 13 & $8,78 \%$ \\
\hline Other & 4 & $2,70 \%$ \\
\hline Friend & 15 & $10,14 \%$ \\
\hline Experimentig & 93 & $62,84 \%$ \\
\hline
\end{tabular}




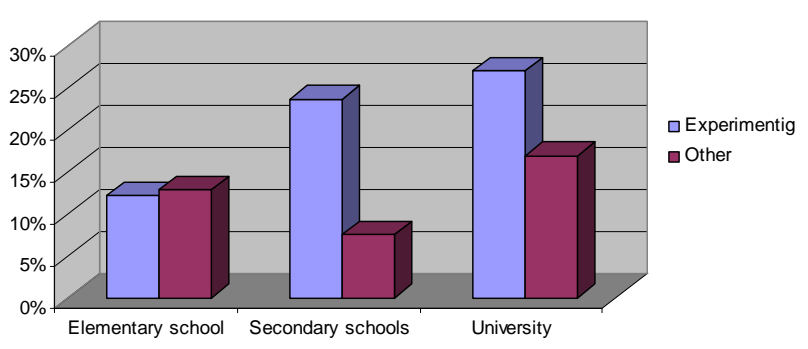

Figure 2. Learning through a period of schooling

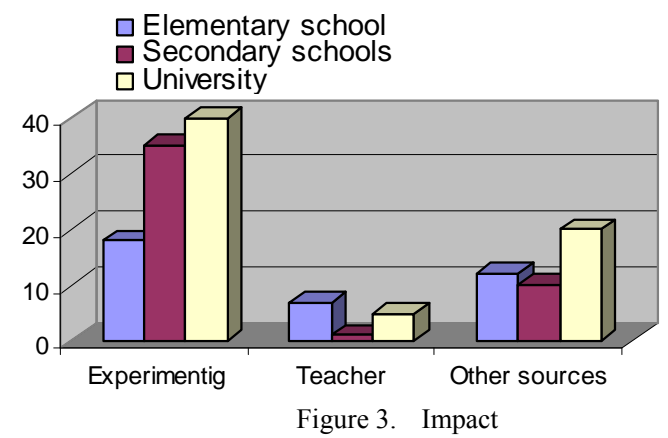

ary schools

$\square$ University

Figure 3. Impact
It can be seen from the Fig. ${ }^{\circ}$. that the experimenting is the basic source of knowledge in all age groups, followed by support other sources, while the impact of formal education is on third place in importance.

The biggest impact of formal education is to the students during the elementary school. In high school the impact is minimal, while the University is growing again.

So far we have analyzed the changes in the factor that is evaluated during the most important education in the respondents.

In the survey, we asked the respondents to individually assess the impact of each of the listed factors on their computer literacy. So we got a Table III and Fig. ${ }^{\circ} 4$ that shows us more precisely relations between factors and their change during the training.

TABLE III.

RELATIONS BETWEEN FACTORS

\begin{tabular}{|l|c|c|c|c|c|}
\hline & $\begin{array}{c}\text { Family } \\
\text { member }\end{array}$ & Teacher & Other & Friend & $\begin{array}{c}\text { Experi- } \\
\text { mentig }\end{array}$ \\
\hline University & 13 & 5 & 0 & & 40 \\
\hline Secondary schools & 4 & 1 & 2 & 4 & 35 \\
\hline Elementary school & 6 & 7 & 2 & 4 & 18 \\
\hline
\end{tabular}

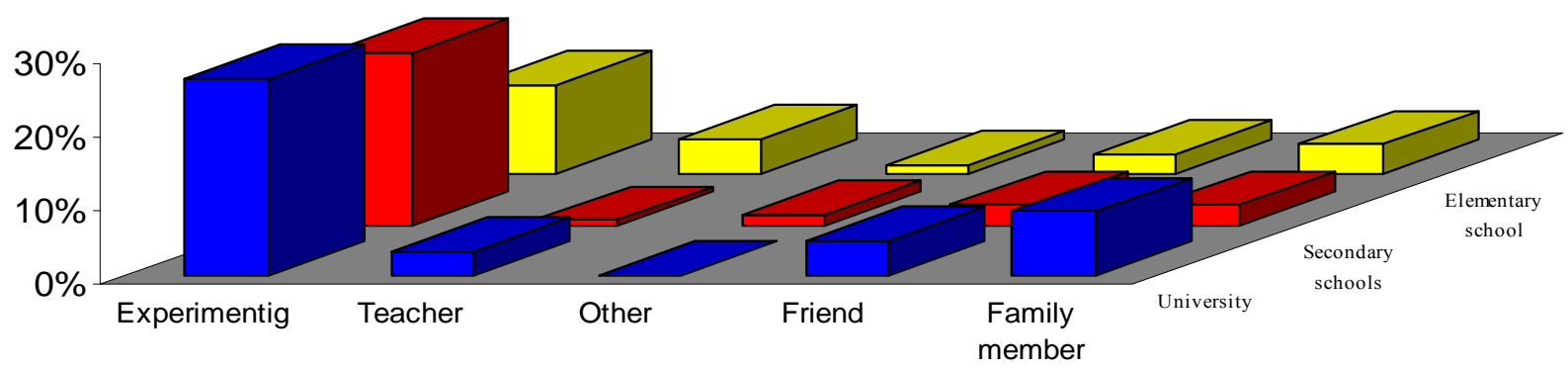

University

Secondary schools

Elementary school

Figure 4. Relations between factors

As we saw in the Fig. ${ }^{\circ}$, experimenting is the most important factor for computer literacy throughout the whole period of schooling. This result is consistent with the results of some earlier studies [12].

We requested of the respondents, that in addition to determining the most important factor, they assess the grade of importance of each of these factors on their computer literacy. On this graph we see the assessment of these grades of each factor separately and we can see that the impact of formal education is higher than it is to conclude from the previous graph. Formal education is not the most important factor in any of the monitored periods, but in two periods (elementary schools and faculty) it is in second place by the ratings of importance, while in the period of secondary school it is on last place in importance. It is apparent that high school period leads to dramatic changes in the relationships among factors in the otherwise consistent data. During this period formal education fall from second to last place in importance among the factors. Without this decline in the influence this factor would be on second place in importance in total.
On the Fig. ${ }^{\circ} 6$, we can see the importance of various factors for all groups. Here we can see that the formal education is on third place in importance, but also very close to factor "Friends" witch is on second place. This division would be significantly different wihout significant change in importance during the period of secondary school. We can conclude that although formal education is not the most important factor, it significantly affects the computer literacy.

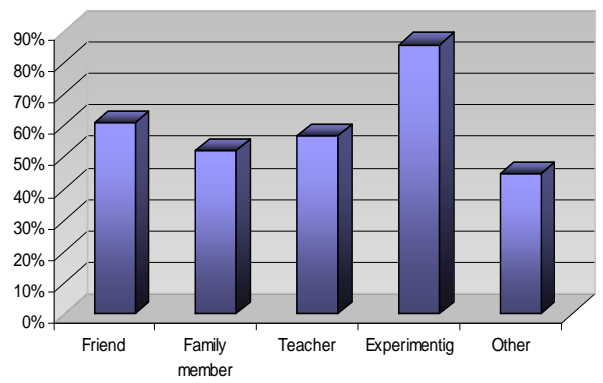

Figure 5. Importance of various factors for all groups 


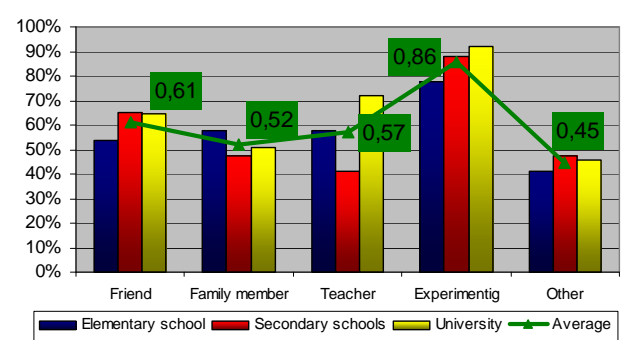

Figure 6. Relations between factors - cumulative

\section{CONCLUSION}

In the modern environment computer literacy is basic and necessary knowledge. Computer technology is present at almost any aspect of modern life, and lack of those skills can exclude one from advance in professional and personal life. During the period of formal education the education system tries to ensure necessary level of computer literacy, and this study tried to reveal the success of this attempt. We noticed that the importance of formal education on computer literacy vary during the period of schooling.

Formal education has the greatest impact on students (and their computer literacy) during the period of elementary school. This is expected because this population is still not ready for self-learning, and part of them still did not come in contact with computers through their social circle and therefore they most rely on the school as source of knowledge. Therefore, this period should be used to give students foundations of computer literacy. It should be noted that unlike other factors, formal learning systemizes knowledge and such knowledge is better and more enduring basis for the upgrade. High school is a period in which formal education has the smallest impact on computer literacy of students. Reasons for this may be multiple, and it should be further explored. During this period the influence of authorities representing the school and parents are falling, while the influence of friends significantly increased. Because of these irregularities in the data, this is the period on which we should particularly pay attention. Additional research followed by changes in approach, and curriculum alterations in this period can enable significant progress. One way of achieving this is to concentrate on use of computers as tools for the field of education and work that students are interested in. In the period of the University education, two most important factors are: self-learning and formal education. This might explain by the fact that in this period students already possess some basic knowledge and reached the optimum level of computer literacy witch allow them more independent learning. On the other hand, computer knowledge that they get through the formal education in this period are specific and is not possible to obtain them from other (informal) sources. For this reason, in this period selflearning has a maximum grade in relation to all observed periods. Influence of formal education is on the second place and shows the growth, while all other factors are in decline in this age group. This is the period where we noticed the largest grade of impact of formal education compared to all age groups.

\section{A. Foundation for future research}

As most interesting period for further research we can point the period of high school. This is a period whith inconsistency in relation to the other two periods, and also a period in which formal education has the least impact on students. Further research could explore the reasons why the impact of formal education in computer literacy declines in high school and provide guidelines for possible improvements.

\section{REFERENCES}

[1] J. J.Beckers, H. G. Smith, "The structure of computer anxiety: a six-factor model", Computers in Human Behavior, vol. 17 (1), p. 35-49, 2001. (doi:10.1016/S0747-5632(00)00036-4)

[2] G. Beekman, Computer confluence. Exploring tomorrow's technology, 6th Edn, Upper Saddle River, NJ: Prentice Hall, 2005

[3] P. Coffee, "Computer literacy isn't kid stuff", eWeek, vol. 23(18), Available: http://www.eweek.com/article2/0,1759,1956817,00.asp , 2006.

[4] W Creighton, M Kilcoyne, R Tarver, S Wright, " Computer Literacy Levels of Students Enrolling in a Post-Secondary Computer Applications/Information Technology Course", Information Technology Learning And Performance Journal, vol24(1), 2006

[5] P. Davis, "What computer skills do employers expect from recent college graduates?", THE Journal, vol. 25(2), p. 74-79, 1997.

[6] L. Grandell, P. Kinnunen, "Teenagers, Computing and Occupational Desires - A Gender Study of Various Factors", Proceedings of the 5th Baltic Sea Conference on Computing Education Research, p. 73-80, 2005.

[7] J. Higdon, "The evolution of computer literacy for perservice teachers", Retrived January 2002. from http://www.coe.uh.edu/ insite/elec_pub/html1995/092.htm

[8] A. Loveless, D. Longman, "Information literacy: innuendo or insight?", Education and Information Technologies, vol 3(1),p. 27 401998 (doi:10.1023/A:1009646204674)

[9] A. Luerhmann, "Computer literacy - What should it be?", The Mathematics Teacher, vol. 74(9), 1981.

[10] N. Manowaluilou, The Importance Of Undergraduate's Computer Competency And Information Literacy Skills: Marketing Faculty's Perspectives In Thailand, Dissertation thesis, University of Missouri - Columbia, 2008.

[11] C. Orr, D. Allen, S. Poindexter, "The effect of individual differences on. computer attitudes: an empirical study", Journal of end user computing, 2001.

[12] T. A. Poynton, " Computer literacy across the lifespan: a review with implications for educators", Computers in Human Behavior, vol. 21 (6), p. 861-872, 2005. (doi:10.1016/j.chb.2004.03.004)

[13] SEUSISS PROJECT, Surveys of European Universities Skills in Informatin and Communication Technology for Staff and Students - Final Report, Retrived January 2009. from http://www.intermedia.uib.no/seusiss

[14] D. Stephens, C. Creaser, "Information Science student IT experience and attitude toward computers: results of a five-year longitudinal study", ITALICS, Innovation in Teaching And Learning in Information and Computer Sciences E-JOURNAL, vol 1 (2), 2002.

[15] The American Heritage of the English Language, Fourth Edition Copyright (C) by Houghton Mifflin Company. Published by the Houghton Mifflin Company, New York, 2002.

[16] M. J. Tsai, "Do male and female students often perform better then female students when learning computers?: A study od Taiwanese eight graders' computer education trough strategic and cooperative learning", Journal of Educational and Computing Research, vol. 26(1), p.67-85, 2002 (doi:10.2190/9JW6-VV1P-FAX8-CGE0)

\section{AUTHORS}

F. A. M. Milić (milic.melita@gmail.com) is with Mellinia d.o.o, Pula, Croatia PhD student on Faculty of Organizations and Information, University of Zagreb, Varazdin

S. B. I. Škorić (skoric.igor@ gmail.com) is with FINA d.o.o, Pula, Croatia, PhD student on Faculty of Organizations and Information, University of Zagreb, Varazdin.

This work was supported in part by the MIPRO, Croatia. This article was modified from a presentation at The 32nd International Convention MIPRO on information 2009, Opatija, Croatia. Manuscript received, ${ }^{\text {st }}$ March 2010. Published as resubmitted by the authors 16 March 2010 . 